\title{
Functional and structural studies of ileal reservoirs used for continent urostomy and ileostomy
}

\author{
B M PHILIPSON, N G KOCK, R JAGENBURG, C ÅHRÉN, L NORLÉN, \\ J W L ROBINSON, AND H MENGE
}

From the Departments of Surgery II, Clinical Chemistry, Pathology and Urology, Sahlgrenska sjukhuset, Göteborg, Sweden; Chirurgie Expérimentale, CHUV, Lausanne, Switzerland, and Klinikum Steglitz, Freie Universität, Berlin, Federal Republic of Germany

SUMmARY The structure and function of the mucosa has been studied in continent ileostomy and urostomy reservoirs, the latter being a receptacle for diverted urine constructed out of ileal tissue. Morphometric evaluation was performed by a microdissection technique and functional studies involved the assessment of L-phenylalanine absorption by the whole pouch in vivo and the uptake of the same amino acid by biopsy samples in vitro. Endoscopic examination revealed fairly homogeneous villous structure in the ileostomy reservoirs. In the urostomies, there was a gradual appearance, as a function of the postoperative time interval, of areas of flat mucosa intermingled with villous regions. When possible, biopsies of the two types of mucosa were studied separately. Even in the villous regions of the urostomies, the size of the villi was smaller in all dimensions than the villi of ileostomy samples. The uptake of phenylalanine in vitro, however, was the same in villous samples from urostomies and in ileostomy biopsies. The absorption of phenylalanine in vivo by the whole pouch was lower in the urostomies. There was a good correlation between amino acid absorption in vivo and in vitro in the ileostomies, but not in the urostomies. This is attributed principally to the variable proportions of avillar and villous mucosa in the latter material, as there is a clear reduction in absorption in vivo in the longest established urostomy pouches.

In 1967 the continent ileostomy was introduced in clinical practice as an alternative to the conventional ileostomy. ${ }^{1}$ The intra-abdominal ileal reservoir constructed with this technique has also been used recently to achieve continence in patients requiring urinary diversion. ${ }^{2} 3$ The mucosa of ileostomy reservoirs underwent structural changes soon after construction, but in long term follow-up, a tendency towards normalisation was noted. ${ }^{4}$ The local absorption of L-phenylalanine in ileostomy reservoirs has been investigated both under clinical and experimental conditions, the results indicating finite, albeit somewhat decreased, absorptive capacity. ${ }^{4} 6$

Morphological studies in 'urostomy' reservoirs have revealed signs of progressive villous atrophy and flattening of the epithelial cells in the mucosa

Address for correspondence: B M Philipson, Kirurgiska kliniken II, Sahlgrenska sjukhuset, S-413 45 Göteborg, Sweden.

Received for publication 6 August 1982 after prolonged exposure to urine. ${ }^{78}$ As urinary diversion via an ileal conduit may lead to metabolic disturbances in patients with reduced renal function, ${ }^{910}$ it seemed of interest to study the absorptive capacity of the reservoir mucosa which had been constantly exposed to urine. For this reason we have examined the local absorption of L-phenylalanine in the reservoirs used for collection of urine and compared the results with those obtained in reservoirs accumulating ileal effluent. In addition, biopsy samples were taken from both series of reservoirs for morphological and functional investigations in vitro.

\section{Methods}

\section{PATIENTS}

Ten patients, seven women and three men, with urinary diversion via a continent ileal reservoir were studied. The mean age was $40 \cdot 8$ years (range $21-65$ years) and the mean postoperative observation time 
25 months (range five months to six years). The indications for the construction of these continent urostomies are shown in Table I. In seven patients, this was a secondary operation because of malfunction of an earlier procedure, whereas in three patients, the continent urostomy was a primary diversion.

Eight patients with continent ileostomies were also studied after proctocolectomy for ulcerative colitis. In this group, there were four women and four men: the mean age was 41.0 years (range $27-63$ years), and mean postoperative observation time 42 months (range six months to six years). All patients gave their informed consent to the experiments.

The investigations were carried out on two consecutive days. On both days the patients had controlled food and fluid intake before the investigation, with avoidance of coffee and tea.

\section{DAY I ABSORPTION OF L-PHENYLALANINE IN} VIVO

Immediately before the study, the reservoir was rinsed with $0.9 \%$ isotonic saline and emptied. Two hundred and fifty millilitres of a test solution containing L-phenylalanine $20 \mathrm{mmol} / 1$ and ${ }^{51} \mathrm{Cr}$ EDTA $5 \mu \mathrm{Ci} / 1$ (non-absorbable marker) dissolved in a Ringer solution $\mathrm{pH} 7.4$ containing $30 \mathrm{mmol} / \mathrm{l}$ glucose was instilled into the reservoir. After instillation, aliquots were taken at two, 10, 20, 30, 40,50 , and 60 minutes, whereafter the reservoir was emptied. Before the samples were taken, the contents were mixed by repeated aspiration and injection of the test solution. Phenylalanine was determined by ion-exchange chromatography (Beckman Amino Acid Analyzer model $120 \mathrm{C}$ ) and ${ }^{51} \mathrm{Cr}$ activity in a conventional $\gamma$-counter. The phenylalanine concentration in the reservoir was corrected for the corresponding ${ }^{51} \mathrm{Cr}$-EDTA activity and the rate of absorption was calculated by linear regression analysis of the relationship between concentration and time. Net water movements across the pouch mucosa cannot be established directly from the changes in ${ }^{51} \mathrm{Cr}$-EDTA activity in view of the fact that fluid is continually entering the

Table 1 Indications for urinary diversion in 10 patients

\begin{tabular}{ll}
\hline Diagnosis & $\begin{array}{l}\text { Number of } \\
\text { patients }\end{array}$ \\
\hline Urinary incontinence & 3 \\
Bladder extrophy & 2 \\
Neurogenic bladder & 2 \\
Interstitial cystitis & 1 \\
Carcinoma of urinary bladder & 1 \\
Carcinoma of uterine cervix & 1 \\
\hline
\end{tabular}

pouch throughout the experimental period, from the ileum or from the upper urinary tract.

\section{DAY 2 EXCISION OF BIOPSY SAMPLES FOR STUDY} IN VITRO

After the emptying of the reservoirs, endoscopy was performed with a cystoscope. The macroscopic appearance of the mucosa was registered and directed biopsies were taken for morphometric studies and uptake in vitro.

\section{MORPHOLOGICAL STUDIES}

Biopsy samples were fixed in Bouinś solution. After dehydration and orientation, they were embedded in plastic, sectioned at $1.5 \mu \mathrm{m}$ and stained with haematoxylin-eosin. The number of mitoses in a given sample magnified $40 \times$ was counted and the average of 10 such measurements was taken as an estimate of the mitotic activity. Other samples were fixed in ethanol/glacial acetic acid $(3: 1, \mathrm{v} / \mathrm{v})$ for 24 hours, then rinsed with and stored in $75 \%$ ethanol. These samples were evaluated morphometrically by microdissection. ${ }^{11} 12$ They were first placed under the dissection microscope with the villous surface facing downwards, flattened and photographed to obtain the serosal area. Next, they were stained with the Feulgen reagent, reorientated so that the villi were facing upwards and again photographed so that the number of villi per unit serosal surface could be estimated. Microdissection was then performed under the stereomicroscope to liberate individual villi and crypts. From each sample, 10 random villi were chosen for the determination of their height, width, and breadth at base and apex; from these values the surface area of the individual villus can be assessed. ${ }^{12}$ Finally, the lengths of 10 random crypts were recorded.

\section{DETERMINATION OF L-PHENYLALANINE}

ACCUMULATION IN VITRO

Three parallel biopsy samples from each patient were incubated for one hour at $37^{\circ} \mathrm{C}$ in Krebs bicarbonate buffer containing $1 \mathrm{mmol} / \mathrm{L} \cdot \mathrm{L}-\left({ }^{3} \mathrm{H}\right)$ phenylalanine and a tracer amount of ${ }^{14} \mathrm{COOH}-$ inulin for the determination of the extracellular space of the specimen. After the incubation, the samples were rinsed, blotted, weighed and dissolved individually in $1 \mathrm{ml}$ Soluene ${ }^{\circledR}-350$ by warming to $55^{\circ} \mathrm{C}$. After the dissolution, the samples were acidified with $100 \mu \mathrm{l} 33 \%$ acetic acid and added to 10 $\mathrm{ml}$ Instagel ${ }^{\circledR}$ for counting in a liquid scintillation spectrometer under conditions chosen to discriminate between the two isotopes. Aliquots of the incubation medium were counted under identical conditions. Under the assumption that the tissue contained $80 \%$ water, the results for each sample 
were expressed as a distribution ratio between intraand extracellular water, by correcting the total uptake of phenylalanine for the extracellular compartment, as determined with inulin. ${ }^{13}$

\section{Results}

Endoscopic examination of ileostomy reservoirs revealed mucosa covering the entire surface of the pouch. The shape of the villi varied from finger-like to club-like, with occasional leaves. In the urostomy reservoirs, there was considerable variation in the endoscopic appearance, dependent on the postoperative interval. In those of recent construction, almost unchanged ileal mucosa persisted. At later stages, greater variation was noted, with the appearance of villous ridges. In three patients with the most long established pouches frankly avillar regions were observed, where underlying vessels were easily discernible. Amongst these areas, there were islands of mucosa with regular intestinal appearance. Figure 1 illustrates these two extremes.

Microscopic examination of biopsy samples of ileostomy reservoirs confirmed earlier observations. ${ }^{4}$ The villi were stunted and the crypts were lengthened. In one patient, a pronounced inflammation was noted in the lamina propria, accompanied by considerable shortening of the villi. The hetero- geneity of the mucosa from samples of urostomy reservoirs previously observed ${ }^{8}$ was confirmed on microscopic examination. Biopsies from intestinal areas showed shortened villi and lengthened crypts with a normal surface epithelium. The lamina propria and the submucosa disclosed a chronic oedema. The number of inflammatory cells was within normal limits. Biopsies from avillar mucosa showed almost total loss of crypts and a proprian layer covered by a single row of low cubic epithelium. No signs of fibrosis, metaplasia or dysplasia were ever encountered. Two samples from the same long established urostomy pouch are contrasted in Fig. 2: one portion of the mucosa reveals islands of intestinal appearance with villi and lengthened crypts, whereas the other portion shows a smooth, avillar surface covered with a single row of low cubic epithelium.

Morphometric evaluation of samples from ileostomy reservoirs and of biopsies specifically taken from areas of intestinal appearance in urostomy reservoirs is presented in Table 2 . In two patients, microdissection was not possible because of the absence of villi; this does not mean that the endoscopic samples were taken from avillar regions, as long crypts were encountered in this material. The morphometric data clearly show that the villous height and breadth, as well as the villous surface
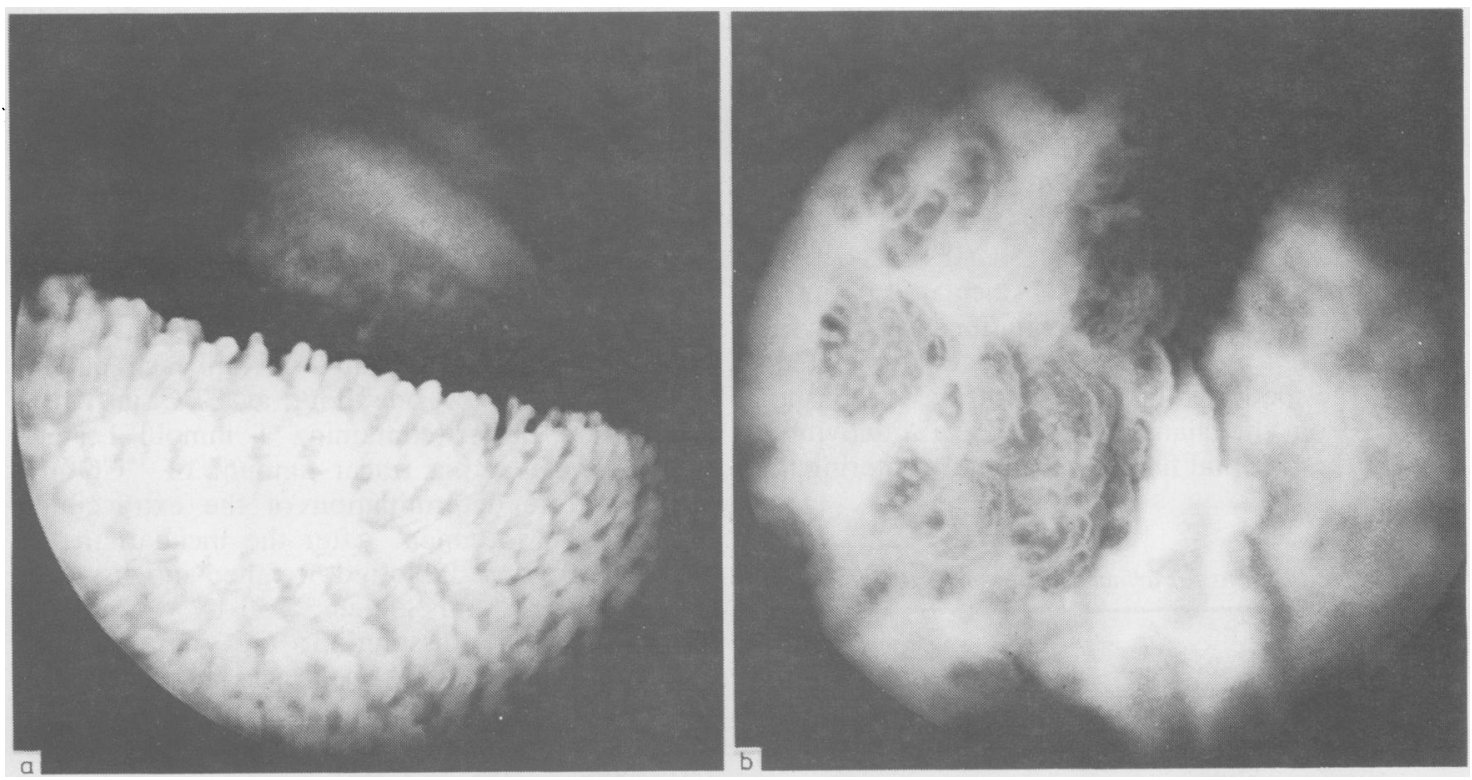

Fig. 1 Endoscopic appearance of urostomy reservoirs. Picture on left shows surface of recently constructed reservoir with finger-like villi. That on the right represents five-year-old reservoir with islands of 'intestinal-like' mucosa surrounded by avillar regions. 


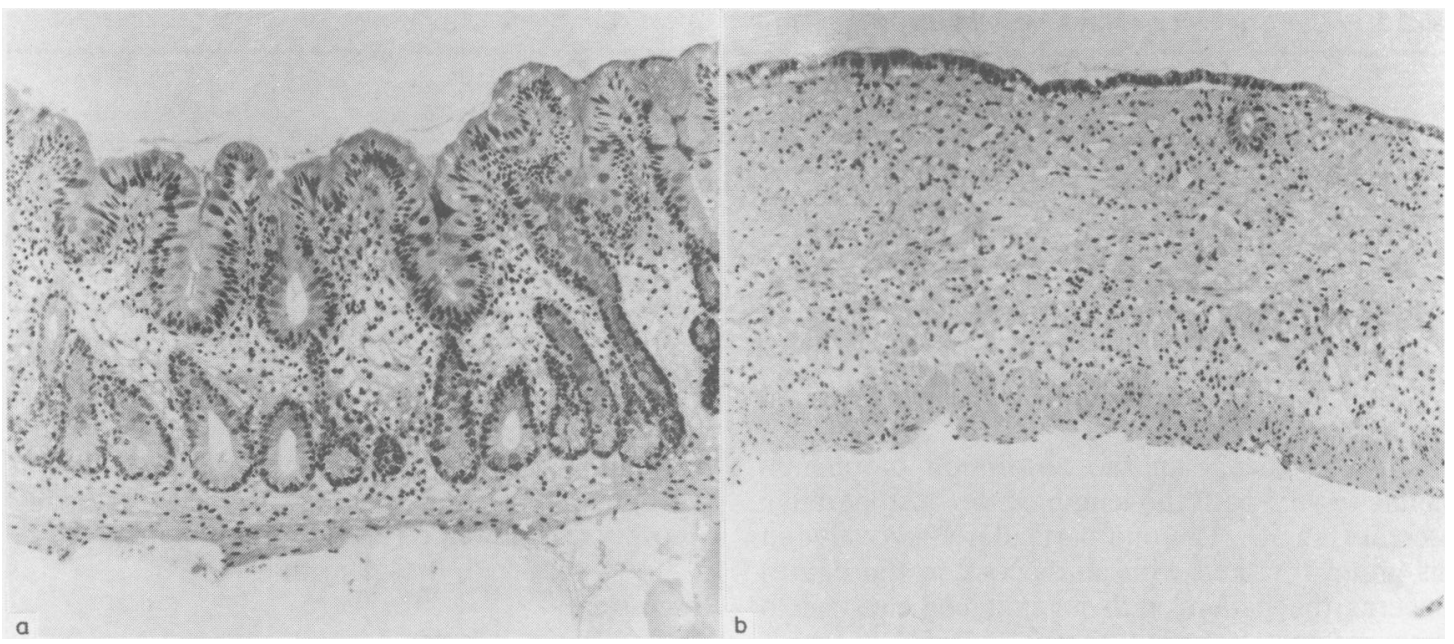

Fig. 2 Microphoto of two areas of a urostomy reservoir five years after construction. On the left, section from 'intestinal-like' island with cylindrical epithelium, whereas on right avillar surface covered with flat epithelial layer is shown.

area and the ratio of the mucosal to serosal surface, were significantly smaller in the urostomy specimens. The number of villi per unit area was significantly larger and the crypt length was smaller in the urostomies.

In addition, the villous height and crypt length were assessed on haematoxylin-eosin stained specimens. There was generally close agreement between the values obtained by the two techniques. Where such agreement did not occur, we tend to ascribe the differences to the heterogeneity of the original samples. We also determined the mitotic activity in the crypts in this material, and found $1.8 \pm 0.32$ mitoses per section in the ileostomy reservoirs and 3.0 \pm 0.94 mitosis in the urostomies (means \pm SEM), difference not significant.

For the evaluation of the uptake of Lphenylalanine in vitro, the biopsy samples from urostomy reservoirs having intestinal or avillar appearances were examined separately. The results in Table 3 show that the samples of intestinal appearance transport this amino acid to the same extent as biopsy samples from ileostomy reservoirs. On the other hand, the three avillar specimens were hardly able to accumulate phenylalanine above a distribution ratio of unity. In addition, the extracellular space of the avillar samples was much greater than that of the other specimens.

The absorption of phenylalanine in vivo was significantly larger in the ileostomy reservoirs than in the urostomies $(43.8 \pm 9.17$ vs $16.6 \pm 4.72 \mu \mathrm{mol} /$ $\min ; t=2.63, p<0.02$ ). In the ileostomy patients, a good correlation was observed between the uptake of phenylalanine in vitro, expressed as a distribution ratio, and the absorption of the same amino acid in vivo (Fig. 3). A similar correlation was not obtained for the urostomy patients.

In the case of the ileostomy reservoirs, there was

Table 2 Microdissection data concerning ileostomy and urostomy mucosae

\begin{tabular}{|c|c|c|c|c|c|c|c|c|}
\hline & \multirow{2}{*}{$\begin{array}{l}\text { Villous } \\
\text { height ( } \mu \mathrm{m})\end{array}$} & \multirow[b]{2}{*}{ width $(\mu m)$} & \multicolumn{2}{|c|}{ breadth $(\mu \mathrm{m})$} & \multirow[b]{2}{*}{ per $\mathrm{mm}^{2}$} & \multirow[b]{2}{*}{ surface $\left(\mathrm{mm}^{2}\right)$} & \multirow{2}{*}{$\begin{array}{l}\text { Ratio } \\
\text { mucosal:serosal } \\
\text { surface }\end{array}$} & \multirow{2}{*}{$\begin{array}{l}\text { Crypt } \\
\text { length } \\
(\mu \mathrm{m})\end{array}$} \\
\hline & & & apex & base & & & & \\
\hline $\begin{array}{l}\text { lleostomy } \\
\text { Urostomy } \\
\text { P }\end{array}$ & $\begin{array}{l}419 \pm 12 \cdot 1 \\
287 \pm 39.4 \\
<0.01\end{array}$ & $\begin{array}{l}145 \pm 5 \cdot 0 \\
148 \pm 5 \cdot 3 \\
\text { NS }\end{array}$ & $\begin{array}{l}286 \pm 12 \cdot 6 \\
157 \pm 7 \cdot 4 \\
<0 \cdot 001\end{array}$ & $\begin{array}{l}325 \pm 21 \cdot 3 \\
184 \pm 7 \cdot 8 \\
<0.001\end{array}$ & $\begin{array}{l}11.9 \pm 0.69 \\
15.6 \pm 1.46 \\
<0.05\end{array}$ & $\begin{array}{l}0.307 \pm 0.0221 \\
0.115 \pm 0.0186 \\
<0.001\end{array}$ & $\begin{array}{l}3.66 \pm 0.361 \\
1.90 \pm 0.377 \\
<0.005\end{array}$ & $\begin{array}{l}391 \pm 28 \cdot 3 \\
258 \pm 34 \cdot 7 \\
<0 \cdot 01\end{array}$ \\
\hline
\end{tabular}

Results are means \pm SEM of eight samples in each group. Two additional samples have been excluded from the urostomy group, as they possessed no villi for dissection; they did, however, possess crypts and so they did not represent samples of the smooth mucosa discussed in the text and illustrated in Fig. 2. Probability of difference between populations evaluated by $t$ test $(\mathrm{NS}=$ not significant at $\mathrm{p}<0.05)$. 
Table 3 L-phenylalanine accumulation by biopsies in vitro

\begin{tabular}{lllr}
\hline & Extracellular space $(\%)$ & $\begin{array}{l}\text { Phenylalanine uptake } \\
\text { umol/100 mg fresh tissue }\end{array}$ & Distribution ratio \\
\hline 1. Ileostomies $(\mathrm{n}=8)$ & $23 \pm 4 \cdot 2$ & $0 \cdot 57 \pm 0 \cdot 098$ & $8 \cdot 2 \pm 1 \cdot 37$ \\
2. Urostomies - villous samples $(\mathrm{N}=10)$ & $36 \pm 2 \cdot 7$ & $0 \cdot 59 \pm 0 \cdot 104$ & $11 \cdot 1 \pm 2 \cdot 16$ \\
3. Urostomies - avillar samples $(\mathrm{N}=3)$ & $63 \pm 1 \cdot 9$ & $0 \cdot 11 \pm 0 \cdot 013$ & $2 \cdot 2 \pm 0 \cdot 49$ \\
$\mathrm{t}_{1-2}$ & $2 \cdot 61^{*}$ & $0 \cdot 12$ & $1 \cdot 11$ \\
$\mathrm{t}_{2-3}$ & $8 \cdot 17 \ddagger$ & $4 \cdot 50 \ddagger$ & $4 \cdot 00 \dagger$ \\
\hline
\end{tabular}

Results are means \pm SEM of number of samples stated. Statistical evaluation of difference by $t$ test. ${ }^{*} \mathrm{p}<0.05 ; \mathrm{p}<0.01 ; \neq \mathrm{p}<0.001$.

no obvious change in the absorption of phenylalanine in vivo with the length of the postoperative interval (Fig. 4). The one particularly low value in this group (marked with an asterisk in the figure) concerns the patient with an inflamed mucosa to whom we have referred above. In contrast, there was a marked trend in the urostomy patients towards reduced phenylalanine absorption as a function of time. In our experience, regions of avillar mucosa first appeared after 20 months' observation time. For that reason, we have considered patients with reservoirs established for more than 20 months separately. In all five urostomy reservoirs of that age, the absorption of phenylalanine was less than $16 \mu \mathrm{mol} / \mathrm{min}$, whereas in all

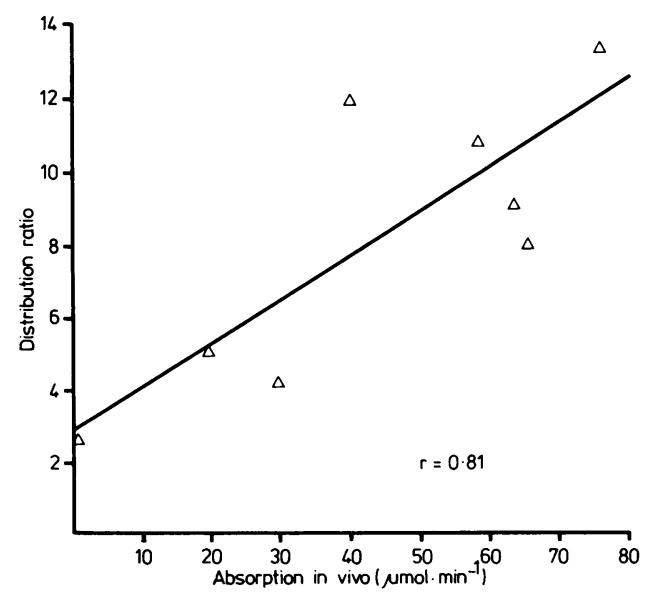

Fig. 3 Correlation between uptake of L-phenylalanine in vitro, expressed as distribution ratio between intra- and extracellular concentrations, and absorption of same amino acid in vivo in continent ileostomy reservoirs. ileostomies with the exception of the patient with inflammation of the mucosa, the corresponding absorption was greater than $19 \mu \mathrm{mol} / \mathrm{min}$.

\section{Discussion}

In ileostomy reservoirs, even on a long term basis, the villous structure of the mucosa is maintained with relatively discrete modifications, despite alterations in the intraluminal environment. Indeed, according to our previous studies, a reduction in villous height and an increase in crypt length, accompanied by an increase in cell turnover, develop during the early postoperative period, whereas these parameters tend to normalise at later

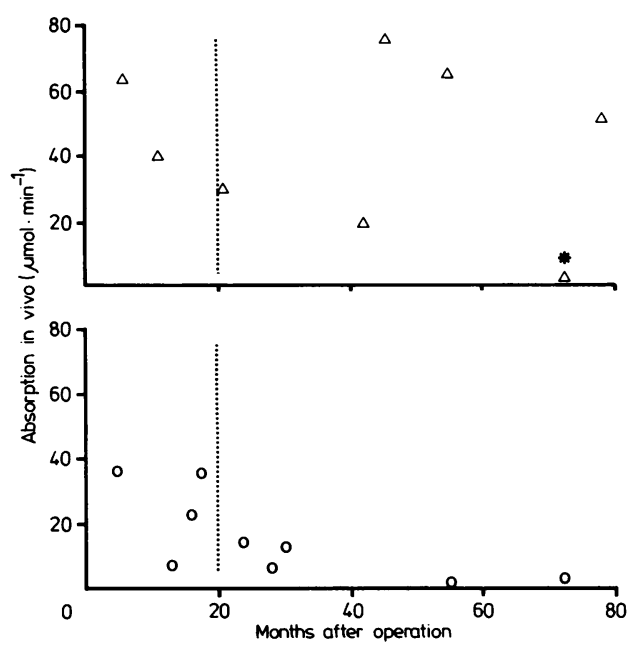

Fig. 4 Absorption of L-phenylalanine in vivo in ileostomy (upper panel) and urostomy (lower panel) reservoirs as function of postoperative time interval. Asterisk refers to patient with pronounced inflammation of lamina propria and reduced villous height. Vertical dotted line refers to postoperative time interval after which heterogeneity of mucosal structure of urostomy was encountered at endoscopy. 
stages. ${ }^{5}$ In contrast, there are progressive alterations in the mucosal structure of the urostomy reservoirs. Although systematic long term studies are not yet available, owing to the novelty of the technique, it appears that the normal ileal mucosa is gradually transformed into a structure lacking villi and crypts, but resembling a lamina propria covered by a cubic or flat epithelium. ${ }^{8}$ Nevertheless, in all cases studied up to the present time, some areas of mucosa with intestinal features persist. The structure of these 'intestinal islands', with their lengthened crypts and shortened villi, and occasional flat mucosa with coeliac-like characteristics, ${ }^{8}$ provides some indication as to how this mucosal transformation has developed. Changes of this nature only occur when the noxious influence is present in the lumen. ${ }^{14} \mathrm{We}$ therefore consider the changes that we have observed to be an adaptive phenomenon associated with the long term exposure to urine.

The fact that even the smooth areas of the urostomy mucosa which no longer exhibit intestinal characteristics are covered with a monocellular epithelial layer requires some comment. In earlier studies we have noted the occasional occurrence of areas of denuded mucosa ${ }^{78}$ which has been interpreted in terms of intermittent erosion of the surface epithelium. It is known that the healing of chemically produced ulcers occurs by the progression of a unicellular layer from surviving crypts; ${ }^{15}$ we believe that in the present instance, the flat or cubic epithelium that covers the lamina propria of the smooth areas of the urostomy pouches originates in a similar manner.

The biopsy samples from urostomy reservoirs with villous structure exhibited an unexpectedly good capacity for phenylalanine uptake in vitro. Indeed, the distribution ratio established by these specimens was as high as that of the ileostomy biopsies. Hitherto no data are available, to our knowledge, on the uptake of amino acids by normal human ileal biopsy samples, so it is not known whether these distribution ratios correspond to the norm. On the other hand, when avillar samples were incubated in the same fashion, the uptake of phenylalanine was found to be much smaller, with the establishment of distribution ratios that are only slightly greater than unity.

Whereas there was a good correlation between the absorption of phenylalanine in vivo and in vitro in the ileostomy reservoirs, a similar correlation did not exist in the urostomy patients. Two factors may be responsible for this observation: first, the proportions of smooth and 'intestinal-like' mucosa in the urostomy pouches was variable. Whereas the uptake of phenylalanine in vitro was assessed separately on the two types of tissue - and differed considerably in these - the absorption in vivo was necessarily determined for the whole pouch. This incidentally explains why the absorption of phenylalanine in vivo tends to fall with an increasing postoperative interval, as the proportion of smooth mucosa appears to increase with time. No such functional impairment was observed in vitro in the 'intestinallike' biopsies. Secondly, the absorption of relatively high concentrations of amino acids in vivo is believed to occur simultaneously by transcellular and paracellular pathways. ${ }^{16}$ In the urostomy reservoirs into which hypertonic urine is continually flowing, there is likely to exist a permanent paracellular bulk flow of water from the blood to the lumen via the paracellular shunts. This would tend to hinder any paracellular absorption of phenylalanine, and could contribute to the low values for this process registered in the urostomy pouches.

In the previous publication we reported kidney function data for patients with long term urostomy reservoirs and found no negative influence of the pouch per se on any parameter. ${ }^{3}$ The present study shows that urine has no acute harmful effect on the intestinal mucosa used for the construction of the pouch. But in the long term, we have observed a gradual transformation of the ileal mucosa into a less differentiated structure which absorbs less amino acids. It is possible that this structure may also absorb less of the harmful components of urine and actually protect the patient from metabolic disturbances.

This study was supported by grants from the Swedish Medical Research Council (project No. B80-17X-00577-16C) and the Swedish ILCO Association. We are grateful to Harriet Andersson, Kristina Boström, Barbro Ekmark and Elisabet Lindholm (Göteborg), Sylvianne Henriot (Lausanne), and Ursula Feldman (Berlin) for skilful technical assistance.

\section{References}

1 Kock NG. Intra-abdominal 'reservoir' in patients with permanent ileostomy. Arch Surg 1969; 99: 223-31.

2 Kock NG, Nilson AE, Norlén L, Sundin T, Trasti H. Urinary diversion via a continent ileum reservoir. Clinical experience. Scand J Urol Nephrol 1978; suppl 49: 23-31.

3 Kock NG, Nilson AE, Nilsson LO, Norlén LJ, Philipson BM. Urinary diversion via a continent ileal reservoir. Clinical results in 12 patients. $J$ Urol 1982; 28: $469-75$. 
4 Philipson B, Brandberg Å, Jagenburg R, Kock NG, Lager I, Åhrén C. Mucosal morphology, bacteriology and absorption in intra-abdominal ileostomy reservoir. Scand J Gastroenterol 1975; 10: 145-53.

5 Nilsson LO, Kock NG, Lindgren I, Myrvold HE, Philipson BM, Åhrén C. Morphological and histochemical changes in the mucosa of the continent ileostomy reservoir 6-10 years after its construction. Scand J Gastroenterol 1980; 15: 737-47.

6 Philipson B, Kock NG, Robinson JWL, Menge H, Mirkovitch V. Function and structure of continent ileostomy reservoirs in dogs. Gut 1975; 16: 132-6.

7 Hansson H-A, Kock NG, Norlén L, Philipson B, Trasti H, Åhrén C. Morphological observations in pedicled ileal grafts used for construction of continent reservoirs for urine. Scand J Urol Nephrol 1978; suppl 49: 49-61.

8 Philipson BM, Nilsson LO, Norlén L, Kock NG, Åhrén C. Mucosal adaption in ileum after long time exposure to urine: a study in patients with continent urostomy. In: Robinson JWL, Dowling RH, Riecken EO, eds. Mechanisms of intestinal adaption. Lancaster: MTP Press, 1982: 613-20.

9 Creevy CD. Renal complications after ileal diversion of the urine in non-neoplastic disorders. J Urol 1960; 83: 394-7.

10 Giesy JD, Hodges CV. Flaccid paralysis associated with hyperchloremic acidosis and hypokalemia following ileal loop urinary diversion. J Urol 1965; 94: 243-6.

11 Clarke RM. Mucosal architecture and epithelial cell production rate in the small intestine of the albino rat. $J$ Anat 1970; 107: 519-29.

12 Lorenz-Meyer H, Köhn R, Riecken EO. Vergleich verschiedener morphometrischer Methoden zur Erfassung der Schleimhautoberfläche des Rattendünndarms und deren Beziehung zur Funktion. Histochemistry 1976; 49: 123-9.

13 Robinson JWL, Mirkovitch V. The recovery of function and microcirculation in small intestinal loops following ischaemia. Gut 1972; 13: 784-9.

14 Menge H, Robinson JWL, Riecken EO. Anpassungsmöglichkeiten der Dünndarmschleimhaut an verschiedene intraluminale Milieuveränderungen. $Z$ Gastroenterol 1976; 14: 420-33.

15 Stamm B, Mirkovitch V, Winistörfer B, Robinson JWL, Ozzello L. Regeneration and functional recovery of canine intestinal mucosa following injury caused by formalin. Virchows Arch [Cell Pathol] 1974; 17: 13748.

16 Robinson JWL, Antonioli JA. Is paracellular movement of importance in the intestinal absorption of organic solutes? Gastroenterol Clin Biol 1980; 4: 78-86. 